\title{
Harsh occupations, life expectancy and social security
}

\author{
Pierre Pestieau* and Maria Racionero ${ }^{\dagger}$
}

May 2016

\begin{abstract}
Should pension provisions differ by occupation? We study the optimality of allowing the pension policies to differ by occupation when individuals differ in longevity and occupation, longevity is private information but occupation is observable. There is a case for differentiating the pension policy by occupation when longevity is (imperfectly) correlated with occupation. The short-lived workers in the safe occupation are however made worse-off, more so when the social objective includes a higher social weight on short-lived individuals to redress the implicit bias towards long-lived that the unweighted utilitarian objective entails. The maximin criterion ensures equal utility for short-lived workers regardless of occupation but those in the safe occupation consume the most when young, the least when old and retire the earliest. This is achieved by taxing - often quite heavily - their savings and their earnings from prolonged activity.
\end{abstract}

Keywords: longevity, retirement, harsh occupations, tagging

JEL Classification: H21, H55

${ }^{*}$ CREPP, Université de Liège, CORE, TSE and CEPR. 7, Boulevard du Rectorat, Université de Liège, B-4000 Liège (Belgium). E-mail: p.pestieau@ulg.ac.be

${ }^{\dagger}$ Corresponding author. Research School of Economics, Australian National University, ACT 2601 Canberra (Australia). E-mail: maria.racionero@anu.edu.au

This research was supported under Australian Research Council's Discovery Projects funding scheme (project number DP130103580). We are very grateful to two anonymous referees and the Editor of the journal for their helpful suggestions. We are also grateful to Marc Fleurbaey, Laurence Jaquet and Etienne Lehmann for comments and suggestions. We also thank participants at the Workshop on the Economics of Taxation, the XXI Encuentro de Economía Pública, the special session on "Equity, Pensions, Death" of the 2014 Social Choice and Welfare Meetings, the Public Economic Theory 2015 conference, as well as the NATSEM, NILS, Curtin University and La Trobe University seminar series, for their comments. Errors remain ours. 


\section{Introduction}

Social security systems are under increased fiscal pressure due to the impact of population ageing. With increasing life expectancies it seems reasonable to expect individuals to work longer. In recent years many countries have increased the legal age of retirement and other countries are considering doing so. ${ }^{1}$ The chances of reaching and living retirement in good health differ however significantly among individuals. Sanzenbacher et al. (2015) find that, even though life expectancies at 65 have indeed increased for all levels of educational attainment in the last decades in the US, the gains have been much greater for those in the top quartile, widening the life expectancy gap. Most studies that try to assess life expectancy differentials focus on educational background. Cambois et al. (2011) argue, however, that occupation is the relevant criterion in the debate concerning the age of retirement. They accordingly compute life-expectancies and health-expectancies at 50 and 65 for different occupational categories and find relatively large inequalities. For instance, 50 year old male workers in manual occupations can expect to live on average 5 years less than those in highly-qualified occupations. In this paper we study the optimality of allowing the pension policies, and in particular the retirement age, to differ by occupation.

Special pension provisions are indeed a feature of many OECD economies and are the subject of an on-going public policy debate. As many as 18 OECD member countries have special pension schemes. Zaidi and Whitehouse (2009) discuss their incidence, structure and justification. They mention that such provisions have historically been justified on the grounds that individuals in hazardous jobs, such as underground mining, merit special treatment because this type of work reduces life expectancy, thus shortening the time during which retirement benefits can be enjoyed. They highlight that the most common form is that of a collective concession, where a whole sector (such as underground mine workers, sailors, airline workers and artists) is granted a special treatment in the calculation of pensions and thus provisions towards early retirement.

If longevity and occupation were perfectly correlated (i.e. if all individuals in a given occupation had the same life expectancy) it would suffice to have a single special pension policy for each occupation. Unfortunately, in reality, administrators are unable to observe each individual's longevity and the correlation between longevity and occupation fails to be perfect. In this paper we

\footnotetext{
${ }^{1}$ Several papers have evaluated the effects of such reforms - see recent contributions by Bielecki et al. (2016), Mao et al. (2014), and Sanchez-Martin (2010).
} 
accordingly study the optimal design of pension schemes in an asymmetric information framework. Individuals differ in longevity and occupation. Longevity is private information but is (imperfectly) correlated with occupation, which can be observed.

The public economics literature has not delved much into the relationship between occupation, longevity and retirement. Previous contributions have explored the link between disability and retirement. Cremer et al. (2004, 2007) study the design of optimal social security schemes when disability is not readily observable. They use two devices to elicit information on disability: costly disability tests and self-selection. A downward distortion on retirement age (i.e. earlier retirement) for those who claim to be disabled is shown to play a role in preventing healthy workers from mimicking disabled ones when disability is not observable. Cremer et al. (2007) show that this downward distortion on retirement age can be partially relaxed by introducing error-proof but costly disability tests. In a recent paper Pestieau and Racionero (2016) extend Cremer et al. (2007) by incorporating occupations, and assuming imperfect correlation between disability and occupation. They explore the possibility of differentiating the social security policy by occupation, and compare the results with those achieved with disability tests. Their numerical simulations illustrate that tagging by occupation is preferred to testing when the audit technology is relatively expensive and/or the ratio of disabled to healthy workers markedly differ across occupations.

In this paper we abstract from tests and focus on differential longevity instead of differential health status. The distinction is not innocuous. We show that the utilitarian social objective induces redistribution from short- to long-lived individuals in our setting with differential longevity. This was not the case with differential health status, where the utilitarian objective implied redistribution from healthy to disabled individuals. In order to partially redress the implicit bias towards long-lived individuals that the unweighted utilitarian objective entails, we explore the implications of increasing the social weight on the short-lived individuals.

We adopt a simple setting with two periods. During the first period, of identical length for all, the individuals work, consume and save. During the second period, of uneven length depending on longevity, individuals work, retire and consume the sum of their earnings in second period, their savings and public pension benefits (if any). To make the presentation simple, we assume that there are only two occupations and two longevity types. Each worker learns their longevity type during the first period, with a higher proportion of individuals learning that they are short-lived in the 
harsh occupation. We make the reasonable assumption that the disutility of prolonged activity in the second period is inversely related to longevity. In other words, a worker who expects a shorter life has a higher disutility from delaying retirement than one with a longer life expectancy. We employ an optimal non-linear taxation approach: i.e. we identify the optimal bundle of consumption in both periods and retirement age for each type of individual, and show how the optimal solution can be implemented via a non-linear tax/transfer scheme.

We consider two second-best problems: in the first case the social security policy is constrained to be the same across occupations (i.e. special pension provisions for harsh occupations are ruled out); in the second case tagging by occupation is allowed. We show that short-lived workers face marginal distortions on savings and prolonged activity: they are induced to consume more when young than when old and to retire earlier. When the pension policies are allowed to differ by occupation the distortions are larger for the short-lived workers in the safe occupation. We also show that an increase in the social weight on short-lived individuals can make short-lived workers in the safe occupation worse off, particularly if the proportion of short-lived individuals in the safe occupation is sufficiently small. The combination of tagging and increased social weight on shortlived individuals harms the short-lived workers in the safe occupation. This result suggests that tampering with the social weight placed on short-lived individuals is a rude instrument to correct for the implicit bias towards long-lived when pension policies are allowed to differ. The maximin objective ensures that short-lived workers achieve the same utility regardless of occupation but this is achieved with relatively large distortions on short-lived workers in the safe occupation: they consume the most in the first period, the least in second period and retire the earliest (earlier than the short-lived workers in the harsh occupation). ${ }^{2}$

For most of the paper we assume that the wage is the same in both occupations and that the occupation is given. The equal wage assumption allows us to focus on the differential longevity aspect and abstract from the standard redistribution associated with heterogeneous wages. In the real world, however, wages may differ by occupation. Accordingly, we discuss the implications of allowing the wages to differ across occupations. Also, the resulting policies in the benchmark model imply in general expected utility differences across occupations. We explore the consequences of

\footnotetext{
${ }^{2}$ The results are in the same vein as those of Fleurbaey et al. (2014, 2016) who show that, if one takes an ex post viewpoint, priority should be given to first-period consumption.
} 
imposing equality of expected utility across occupations. This constraint ensures that the optimal policy does not favour any particular occupation.

The rest of the paper is organised as follows. In section 2 we present the model and the laissezfaire outcome. In section 3 we derive the first-best benchmark solution for a weighted utilitarian social objective. In section 4 we analyze the second-best asymmetric information problem: first without tagging (i.e. when the social security policy is common across occupations), and then with tagging (i.e. when the social security policy is allowed to differ by occupation). We perform numerical simulations in section 5 to shed more light on the results. We conclude in section 6 .

\section{The model}

We consider a society in which individuals differ in longevity and occupation. The longevity, represented by $\ell_{i}$, is private information. We assume that individuals can be either long-lived or short-lived: ${ }^{3} \ell_{L}>\ell_{S}$, where $L$ and $S$ stand for long-lived and short-lived, respectively. The occupation, represented by subscript $j(j=1,2)$, is observable. $n_{j}$ stands for the proportion of workers in occupation $j$ and $p_{j}$ represents the proportion of workers in occupation $j$ that are shortlived. We assume that $p_{1}>p_{2}$. Accordingly, we refer to occupation 1 as harsh and occupation 2 as safe. We take occupation as given and assume that both occupations yield the same wage $w$. This assumption allows us to focus on the effects of differential longevity on pension schemes and abstract from the standard redistribution associated with heterogeneous wages. ${ }^{4}$

Individuals live for 2 periods. In the first period, of length normalized to 1, individuals work full time and earn wage $w$, consume $c_{i j}$ and save $s_{i j}$. At some point in the first period individuals learn their longevity type. In the second period, of length $\ell_{i}$, individuals work for an endogenous amount of time $z_{i j}$ and consume $d_{i j}$, which, in the absence of public pensions, is financed from their second-period earnings and savings (i.e. there are no bequests).

There are hence four types of individuals $i j(i=S, L$ and $j=1,2)$ with preferences represented by the following utility function:

$$
U_{i j}=u\left(c_{i j}\right)+\ell_{i} u\left(d_{i j}\right)-v\left(z_{i j} ; \ell_{i}\right)
$$

\footnotetext{
${ }^{3}$ At the outset all individuals are alike but as time goes by they learn their longevity type.

${ }^{4}$ In the numerical illustration we explore how the results change when wages are allowed to differ across occupations. We also explore the consequences of imposing equality of expected utility across occupations. This constraint ensures that individuals are ex-ante indifferent between occupations and that it is possible to have workers in both occupations if individuals are allowed to choose. A more detailed occupational choice version will be considered in further research.
} 
where, as mentioned above, $c_{i j}$ represents first-period consumption, $d_{i j}$ represents second-period consumption and $z_{i j}$ represents second-period labour supply. The length of active life is therefore $1+z_{i j}$. The utility of consumption in both first and second periods function $u($.$) is assumed to be$ strictly increasing and concave (i.e. $u^{\prime}()>$.0 and $\left.u^{\prime \prime}()<0.\right)$. The disutility function of prolonged activity $v\left(z_{i j} ; \ell_{i}\right)$ is assumed to be increasing and convex (i.e. $v^{\prime}\left(z_{i j} ; \ell_{i}\right)>0$ and $v^{\prime \prime}\left(z_{i j} ; \ell_{i}\right)>0$, where the first and second derivative are taken with respect to the choice variable $z_{i j}$ ). We also assume that this disutility depends on the longevity of individuals $\ell_{i}$ and, in particular, that the marginal disutility of working longer is higher for short-lived individuals: $v^{\prime}\left(z ; \ell_{S}\right)>v^{\prime}\left(z ; \ell_{L}\right)$ for all $z$. The marginal rates of substitution of first- for second-period consumption, and of labor for consumption in second period, are given respectively by

$$
M R S_{c d}^{i j}=\frac{u^{\prime}\left(c_{i j}\right)}{u^{\prime}\left(d_{i j}\right)} \text { and } M R S_{z d}^{i j}=\frac{v^{\prime}\left(z_{i j} ; \ell_{i}\right)}{u^{\prime}\left(d_{i j}\right)} .
$$

The latter implies that the indifference curve of the short-lived individuals is steeper at any given allocation in the $(z, d)$-space.

The social security policy consists of a bundle $\left(c_{i j}, d_{i j}, z_{i j}\right)$ of consumption, in first and second periods, and of labour supply in second period (i.e. retirement age) for each individual $i j$. This social security policy can be implemented by a non-linear tax on savings $t\left(s_{i j}\right)$ and a non-linear tax on prolonged activity $T\left(z_{i j}\right) .{ }^{5}$ The consumer $i j$ 's problem under the non-linear tax schedules $t\left(s_{i j}\right)$ and $T\left(z_{i j}\right)$ can be written as:

$$
\max _{s_{i j}, z_{i j}} u\left(w-s_{i j}\right)+\ell_{i} u\left(\frac{s_{i j}-t\left(s_{i j}\right)+w z_{i j}-T\left(z_{i j}\right)}{\ell_{i}}\right)-v\left(z_{i j} ; \ell_{i}\right) .
$$

The first-order conditions (hereafter FOCs) are:

$$
\begin{aligned}
& F O C\left(s_{i j}\right): u^{\prime}\left(c_{i j}\right)(-1)+\ell_{i} u^{\prime}\left(d_{i j}\right) \frac{1}{\ell_{i}}\left(1-t^{\prime}\left(s_{i j}\right)\right)=0 \\
& F O C\left(z_{i j}\right): \quad \ell_{i} u^{\prime}\left(d_{i j}\right) \frac{1}{\ell_{i}}\left(w-T^{\prime}\left(z_{i j}\right)\right)-v^{\prime}\left(z_{i j} ; \ell_{i}\right)=0 .
\end{aligned}
$$

\footnotetext{
${ }^{5}$ Our approach is that of optimal non-linear taxation, in which the standard parameters of a pension system (namely, payroll tax and pension benefit) do not appear explicitly. To make the link clearer here we start by assuming away the taxation of savings and focus on the taxation of prolonged activity, which is a function of the observable retirement age $z$. Such a tax can be implemented with a flat payroll tax and a pension benefit that depends on the retirement age and be expressed as $T(z)=t w(1+z)-(l-z) b(z)$, where $t$ is the flat tax rate and $b(z)$ is the yearly pension that depends on the retirement age $z$. There is an important empirical literature, pioneered by Gruber and Wise (1999), aimed at measuring $T^{\prime}(z)$, which is called the implicit tax on prolonged activity and yields the net loss that a worker would incur if she decides to work one more year. An optimal (first best) social security scheme would yield a zero marginal tax in order not to distort the retirement decision. When solving the optimisation problem, expressed in terms of payroll tax $t$ and pension benefit $b(z)$, it can be shown that $T^{\prime}(z)=t w+b(z)-(1-z) b^{\prime}(z)$. To have a neutral pension system (i.e. $T^{\prime}(z)=0$ ) the level of benefit must increase with the age of retirement. Introducing a tax on savings adds an additional instrument in the case with two distinct periods.
} 
Rearranging, we obtain that the marginal taxes on savings and on prolonged activity (i.e. postponing retirement) are, respectively: ${ }^{6}$

$$
t^{\prime}\left(s_{i j}\right)=1-\frac{u^{\prime}\left(c_{i j}\right)}{u^{\prime}\left(d_{i j}\right)} \text { and } T^{\prime}\left(z_{i j}\right)=w-\frac{v^{\prime}\left(z_{i j} ; \ell_{i}\right)}{u^{\prime}\left(d_{i j}\right)} .
$$

In a market economy, each individual $i j$ chooses $s_{i j}$ and $z_{i j}$ to maximize (1) subject to firstand second-period budget constraints, $c_{i j}+s_{i j}=w$ and $\ell_{i} d_{i j}=s_{i j}+w z_{i j}$ respectively:

$$
\max _{s_{i j}, z_{i j}} u\left(w-s_{i j}\right)+\ell_{i} u\left(\frac{s_{i j}+w z_{i j}}{\ell_{i}}\right)-v\left(z_{i j} ; \ell_{i}\right) .
$$

The FOCs are:

$$
\begin{aligned}
& F O C\left(s_{i j}\right): u^{\prime}\left(c_{i j}\right)(-1)+\ell_{i} u^{\prime}\left(d_{i j}\right) \frac{1}{\ell_{i}}=0 \\
& F O C\left(z_{i j}\right): \quad \ell_{i} u^{\prime}\left(d_{i j}\right) \frac{1}{\ell_{i}} w-v^{\prime}\left(z_{i j} ; \ell_{i}\right)=0 .
\end{aligned}
$$

Rearranging:

$$
u^{\prime}\left(c_{i j}\right)=u^{\prime}\left(d_{i j}\right)=\frac{v^{\prime}\left(z_{i j} ; \ell_{i}\right)}{w}
$$

The bundle $\left(c_{i j}, d_{i j}, z_{i j}\right)$ depends only on longevity (i.e. we can ignore the subscript for occupation $j$ in the laissez-faire solution) and individuals smooth consumption between first and second periods (i.e. $c_{i}=d_{i}$ for each $\left.i=S, L\right)$. The relationship between the particular combinations chosen, and the levels of utility achieved, by individuals with different longevity is ambiguous without specifying particular functional forms.

We assume in the following that living longer is preferable. ${ }^{7}$ Differentiating $U_{i j}$ with respect to $\ell_{i}$, we have:

$$
\frac{\partial U_{i j}}{\partial \ell_{i}}=u\left(d_{i j}\right)-u^{\prime}\left(d_{i j}\right) d_{i j}-\frac{\partial v\left(z_{i j} ; \ell_{i}\right)}{\partial \ell_{i}} .
$$

It follows that $u(d)>u^{\prime}(d) d$ is sufficient to ensure that utility increases with longevity, which is a standard assumption. ${ }^{8}$ Additional conditions on the disutility of prolonged activity $v(z ; \ell)$ are required to ensure that individuals enjoy some positive amount of time in retirement.

\footnotetext{
${ }^{6}$ The marginal tax on labour earnings from prolonged activity is:$$
T^{\prime}\left(w z_{i j}\right)=1-\frac{v^{\prime}\left(z_{i j} ; \ell_{i}\right)}{w u^{\prime}\left(d_{i j}\right)}
$$

We provide this alternative expression in terms of earnings from prolonged activity to enable comparison with traditional marginal tax rates on income, usually comprised between 0 and 1 .

${ }^{7}$ This is a standard assumption for developed countries and it does not necessarily apply in societies where lifetime resources are scarce. It also implies that such an additional year would be relatively healthy. See on this Pestieau and Ponthière (2014, 2016).

${ }^{8}$ See Eeckhoudt and Pestieau (2008).
} 


\section{The first best: incorporating weights}

The traditional unweighted utilitarian social objective can have undesirable effects when longevity varies across individuals. Indeed, with additive utilities the utilitarian criterion implies redistribution from short- to long-lived individuals. Short-lived individuals are subject to a double penalty: they live fewer years and are made to subsidize those who live longer. ${ }^{9}$ In order to partially redress the implicit bias towards long-lived individuals that the unweighted utilitarian social objective entails we incorporate social weights. We denote by $\gamma_{i}$ the weight on individuals with longevity $\ell_{i}$ $(i=S, L)$. We assume $\gamma_{S}=\gamma \geq 1 / 2$ (and $\left.\gamma_{L}=1-\gamma \leq 1 / 2\right)$, where $\gamma$ could be adjusted in such a way that the utilities of the two types are equalized if so desired. ${ }^{10}$ The Lagrangian for the first-best problem is:

$$
\begin{aligned}
£= & \sum_{j=1,2} n_{j}\left\{\gamma_{L}\left(1-p_{j}\right)\left[u\left(c_{L j}\right)+\ell_{L} u\left(d_{L j}\right)-v\left(z_{L j} ; \ell_{L}\right)\right]+\gamma_{S} p_{j}\left[u\left(c_{S j}\right)+\ell_{S} u\left(d_{S j}\right)-v\left(z_{S j} ; \ell_{S}\right)\right]\right\} \\
& +\mu \sum_{j=1,2} n_{j}\left\{\left(1-p_{j}\right)\left[\left(1+z_{L j}\right) w-c_{L j}-\ell_{L} d_{L j}\right]+p_{j}\left[\left(1+z_{S j}\right) w-c_{S j}-\ell_{S} d_{S j}\right]\right\}
\end{aligned}
$$

where $\mu$ is the Lagrangian multiplier associated with the budget constraint. Rearranging the FOCs we obtain for each type $i j$ :

$$
u^{\prime}\left(c_{i j}\right)=u^{\prime}\left(d_{i j}\right)=\frac{v^{\prime}\left(z_{i j} ; \ell_{i}\right)}{w}=\frac{\mu}{\gamma_{i}} .
$$

As in the laissez-faire, the bundle $\left(c_{i j}, d_{i j}, z_{i j}\right)$ depends only on longevity and involves consumption smoothing between first and second periods (i.e. $c_{i}=d_{i}$ for each $i=S, L$ ). With identical weights on both long- and short-lived individuals the first-best solution is characterized by identical consumption for all and earlier retirement for short-lived individuals (i.e. $c_{L}=d_{L}=d_{S}=c_{S}$ and $z_{S}<z_{L}$, since $v^{\prime}\left(z_{S} ; \ell_{S}\right)=v^{\prime}\left(z_{L} ; \ell_{L}\right)$ and short-lived individuals have a higher marginal disutility from prolonged activity). When a higher social weight is placed on short-lived individuals (i.e. $\gamma>1 / 2$ ), long-lived individuals consume less in both periods $c_{L}=d_{L}<d_{S}=c_{S}$. In addition, $v^{\prime}\left(z_{S} ; \ell_{S}\right)<v^{\prime}\left(z ; \ell_{L}\right)$ : the gap between retirement ages $z_{L}$ and $z_{S}$ increases. If longevity is not observable the incentive for type- $L$ individuals to mimic type- $S$ individuals, which is already present with equal weights, is exacerbated as more weight is placed on short-lived individuals. Given the

\footnotetext{
${ }^{9}$ See Bommier et al. (2011) or Pestieau and Ponthière (2014).

${ }^{10}$ We do not assume a particular value for this social weight. We explore the implications of letting the social weight vary (i.e. compare the equal weights allocation - $\gamma=1 / 2$ - with those achieved with increasingly higher social weights on short-lived individuals $-\gamma>1 / 2)$.
} 
pattern of consumption and retirement in the first-best type- $L$ individuals would be better off with the package offered to type- $S$ individuals:

$$
u\left(c_{L}\right)+\ell_{L} u\left(d_{L}\right)-v\left(z_{L} ; \ell_{L}\right)<u\left(c_{S}\right)+\ell_{L} u\left(d_{S}\right)-v\left(z_{S} ; \ell_{L}\right)
$$

\section{The second best: common versus differentiated policies}

The first-best solution is not feasible when longevity is private information. The social planner needs to design the social security policy so that individuals reveal their true types. We assume first, as a benchmark, that the social planner does not have or cannot use the occupation information (i.e. there is a common social security policy across occupations). We then allow the social planner to differentiate the social security policy by occupation when information about occupation is available and may be used as a tag (accordingly, we call this case tagging by occupation). ${ }^{11}$

\subsection{Common social security policy across occupations}

The Lagrangian for this second-best problem is:

$$
\begin{aligned}
£= & \sum_{j=1,2} n_{j}\left\{\gamma_{L}\left(1-p_{j}\right)\left[u\left(c_{L}\right)+\ell_{L} u\left(d_{L}\right)-v\left(z_{L} ; \ell_{L}\right)\right]+\gamma_{S} p_{j}\left[u\left(c_{S}\right)+\ell_{S} u\left(d_{S}\right)-v\left(z_{S} ; \ell_{S}\right)\right]\right\} \\
& +\mu \sum_{j=1,2} n_{j}\left\{\left(1-p_{j}\right)\left[\left(1+z_{L}\right) w-c_{L}-\ell_{L} d_{L}\right]+p_{j}\left[\left(1+z_{S}\right) w-c_{S}-\ell_{S} d_{S}\right]\right\} \\
& +\lambda\left[u\left(c_{L}\right)+\ell_{L} u\left(d_{L}\right)-v\left(z_{L} ; \ell_{L}\right)-u\left(c_{S}\right)-\ell_{L} u\left(d_{S}\right)+v\left(z_{S} ; \ell_{L}\right)\right]
\end{aligned}
$$

where $\lambda$ represents the Lagrangian multiplier associated with the self-selection constraint that is incorporated to ensure that long-lived individuals do not have incentives to mimic short-lived ones. Rearranging the FOCs, and using $n_{L}=n_{1}\left(1-p_{1}\right)+n_{2}\left(1-p_{2}\right)$ for total number of long-lived individuals in the population and $n_{S}=n_{1} p_{1}+n_{2} p_{2}$ for total number of short-lived individuals in the population, we obtain:

$$
u^{\prime}\left(c_{L}\right)=u^{\prime}\left(d_{L}\right)=\frac{v^{\prime}\left(z_{L} ; \ell_{L}\right)}{w}=\frac{\mu}{1-\gamma+\frac{\lambda}{n_{L}}}
$$

\footnotetext{
${ }^{11}$ Zaidi and Whitehouse (2009) highlight that the most common form of special pension provision in OECD countries is that of a collective concession, where a whole sector (such as underground mine workers, sailors, airline workers and artists) is granted a special treatment. A blanket special pension policy that provides the same treatment to both long- and short-lived workers in a given occupation is not formally analyzed in our paper because, in a situation where long- and short-lived individuals coexist, such a policy would be further away from optimality than the common policy across occupations that provides the same treatment across occupations but allows the treatment for longand short-lived workers to differ within each occupation.
} 
for long-lived individuals, and

$$
u^{\prime}\left(c_{S}\right)=\frac{\mu}{\gamma-\frac{\lambda}{n_{S}}}, u^{\prime}\left(d_{S}\right)=\frac{\mu}{\gamma-\frac{\lambda}{n_{S}} \frac{\ell_{L}}{\ell_{S}}} \text { and } v^{\prime}\left(z_{S} ; \ell_{S}\right)=\frac{1}{\gamma}\left(\mu w+\frac{\lambda}{n_{S}} v^{\prime}\left(z_{S} ; \ell_{L}\right)\right)
$$

for short-lived individuals. Hence:

$$
\begin{gathered}
\frac{u^{\prime}\left(c_{L}\right)}{u^{\prime}\left(d_{L}\right)}=1 \text { and } \frac{v^{\prime}\left(z_{L} ; \ell_{L}\right)}{u^{\prime}\left(d_{L}\right)}=w, \\
\frac{u^{\prime}\left(c_{S}\right)}{u^{\prime}\left(d_{S}\right)}<1 \text { and } \frac{v^{\prime}\left(z_{S} ; \ell_{S}\right)}{u^{\prime}\left(d_{S}\right)}=w \frac{1-\frac{\lambda}{\gamma n_{S}} \frac{\ell_{L}}{1-\frac{\lambda}{\gamma n_{S}}} \frac{v^{\prime}\left(z_{S} ; \ell_{L}\right)}{u^{\prime}\left(d_{S}\right)}<w .}{} \text {. }
\end{gathered}
$$

Proposition 1 (Second best common social security policy across occupations) There is no distortion on long-lived individuals but distortions at both margins - savings and prolonged activity - for short-lived ones.

The second-best solution is accordingly characterized by $c_{L}=d_{L}$ (i.e. consumption smoothing for long-lived individuals) and $c_{S}>d_{S}$ (higher first- than second-period consumption for shortlived individuals). In principle any relationship between $c_{L}$ and $c_{S}$, and between $d_{L}$ and $d_{S}$, is possible depending on the particular value of weight $\gamma$. If both long- and short-lived individuals receive the same weight the second-best solution implies more consumption for long-lived ones: $c_{L}=d_{L}>c_{S}>d_{S}$. If the weight $\gamma$ placed on short-lived individuals is sufficiently large, the inequalities between $c_{L}$ and $c_{S}$, and between $d_{L}$ and $d_{S}$, can in principle be reversed. In order to better illustrate the implications of letting the weight placed on short-lived individuals vary we perform numerical simulations in section 5 .

\subsection{Tagging by occupation}

We explore now an alternative second-best solution that seeks to exploit the differences in longevity across occupations. In particular we analyse whether, and if so how, the social security policy should differ by occupation. The main distinction with respect to the second-best benchmark in which the planner employs a common social security policy for all occupations is that now there is one self-selection constraint for each occupation:

$$
\begin{aligned}
& \left(\lambda_{1}\right): u\left(c_{L 1}\right)+\ell_{L} u\left(d_{L 1}\right)-v\left(z_{L 1} ; \ell_{L}\right) \geq u\left(c_{S 1}\right)+\ell_{L} u\left(d_{S 1}\right)-v\left(z_{S 1} ; \ell_{L}\right), \\
& \left(\lambda_{2}\right): u\left(c_{L 2}\right)+\ell_{L} u\left(d_{L 2}\right)-v\left(z_{L 2} ; \ell_{L}\right) \geq u\left(c_{S 2}\right)+\ell_{L} u\left(d_{S 2}\right)-v\left(z_{S 2} ; \ell_{L}\right),
\end{aligned}
$$


where $\lambda_{j}$ is the Lagrange multiplier associated with the self-selection constraint that ensures that long-lived individuals do not have incentives to mimic short-lived ones in each occupation $j(j=$ 1,2). We obtain:

$$
u^{\prime}\left(c_{L j}\right)=u^{\prime}\left(d_{L j}\right)=\frac{v^{\prime}\left(z_{L j} ; \ell_{L}\right)}{w}=\frac{\mu}{1-\gamma+\frac{\lambda_{j}}{n_{j}\left(1-p_{j}\right)}}
$$

for long-lived individual types $L j(j=1,2)$ and

$$
u^{\prime}\left(c_{S j}\right)=\frac{\mu}{\gamma-\frac{\lambda_{j}}{n_{j} p_{j}}}, u^{\prime}\left(d_{S j}\right)=\frac{\mu}{\gamma-\frac{\lambda_{j}}{n_{j} p_{j}} \frac{\ell_{L}}{\ell_{S}}} \text { and } v^{\prime}\left(z_{S j} ; \ell_{S}\right)=\frac{1}{\gamma}\left(\mu w+\frac{\lambda_{j}}{n_{j} p_{j}} v^{\prime}\left(z_{S j} ; \ell_{L}\right)\right)
$$

for short-lived individual types $S j(j=1,2)$. Hence

$$
\begin{gathered}
\frac{u^{\prime}\left(c_{L j}\right)}{u^{\prime}\left(d_{L j}\right)}=1 \text { and } \frac{v^{\prime}\left(z_{L j} ; \ell_{L}\right)}{u^{\prime}\left(d_{L j}\right)}=w, \\
\frac{u^{\prime}\left(c_{S j}\right)}{u^{\prime}\left(d_{S j}\right)}<1 \text { and } \frac{v^{\prime}\left(z_{S j} ; \ell_{S}\right)}{u^{\prime}\left(d_{S j}\right)}=w \frac{1-\frac{\lambda_{j}}{\gamma n_{j} p_{j}} \frac{\ell_{L}}{\ell_{S}}}{1-\frac{\lambda_{j}}{\gamma n_{j} p_{j}} \frac{v^{\prime}\left(z_{S j} ; \ell_{L}\right)}{u^{\prime}\left(d_{S j}\right)}}<w .
\end{gathered}
$$

Proposition 2 (Second best tagging by occupation) There is no distortion on long-lived workers in both occupations, but the particular bundle $\left(c_{L j}, d_{L j}, z_{L j}\right)$ and level of utility achieved by long-lived workers in occupation $j$ depend on the proportions of short- and long-lived workers in each occupation. There are distortion at both margins - savings and prolonged activity - for shortlived workers in both occupations. The extent of the distortion, the particular bundle $\left(c_{S j}, d_{S j}, z_{S j}\right)$ and level of utility achieved depend on the proportions of short- and long-lived individuals in each occupation.

There is consumption smoothing for long-lived individuals in both occupations - i.e. $c_{L j}=d_{L j}$ for each $j$ - but the consumption level depends on the longevity distributions in each occupation. We can however show that if long-lived workers in a particular (e.g. harsh) occupation consume more they also retire earlier, and are hence better-off, than their counterparts in the other (e.g. safe) occupation. In order to better illustrate the implications of letting the treatment of individuals vary according to their occupation we perform numerical simulations in section 5 .

\section{Numerical illustration}

The analytical formulas above include Lagrange multipliers for which there are no explicit solutions at the level of generality assumed. In this section we present a numerical illustration to shed more 
light on the implications of the different policy options considered above. We focus on the welfare achieved by different types of individuals, because the individual utility level remains comparable across all cases, and pay particular attention to the effects associated with increases in the social weight attached to short-lived individuals.

The functional form we employ is:

$$
U_{i j}=u\left(c_{i j}\right)+\ell_{i} u\left(d_{i j}\right)-v\left(z_{i j} ; \ell_{i}\right)=\ln c_{i j}+\ell_{i} \ln d_{i j}-\frac{1}{\alpha \ell_{i}} \frac{z_{i j}^{\epsilon}}{\epsilon} .
$$

We use $w=100$ and $\varepsilon=2$, as well as $\ell_{L}=1$ and $\ell_{S}=2 / 3$. We also use $\alpha=0.4 .^{12}$ We assume $n_{1}=n_{2}=1 / 2$ (i.e., the proportion of individuals working in each of the two occupations is the same) and focus on the role of varying the proportions $p_{i}$. We start from the benchmark case where $p_{1}=p_{2}=1 / 2$ and explore subsequently the relevant cases where $p_{1}>p_{2}$, when occupation 1 is effectively harsher than occupation 2, keeping the overall proportion of short-lived individuals in the society however constant, so that the role of the different ratios of short- to long-lived workers by occupation is isolated from the role of the overall number of short-lived individuals in the society.

The longevity parameter values above are chosen to fit life expectancy tables: in particular, life expectancy at $50\left(L E_{50}\right)$ for males in Cambois et al. (2011). ${ }^{13}$ By setting the length of a period to be 30 years and considering 55 the threshold between the first period and the second period (it could correspond to the minimum legal age for retirement), the average $L E_{50}$ in a population with half of the individuals of each type is 80 (consistent with a $L E_{50}$ average of 29). A distribution of $\left(p_{1}, p_{2}\right)=(0.8,0.2)$ corresponds to an average longevity of 77.5 and 82.5 in occupations 1 and 2 , respectively, a 5 -year gap that is consistent with the $L E_{50}$ gap between manual workers and highly qualified occupations.

\subsection{Laissez-faire and first best}

We present in Table 1 the results for the laissez-faire and first-best for different social weights $\gamma=0.5$ and $\gamma=2 / 3$. We include for easier interpretation the retirement age, represented by $R$, that would correspond to the normalization mentioned above. Short-lived individuals are worseoff (and long-lived individuals are better off) in the unweighted utilitarian solution than in the

\footnotetext{
${ }^{12}$ This value ensures that individuals do enjoy some positive time at retirement.

${ }^{13}$ See Cambois et al. (2011): Table 2 in p.418.
} 


\begin{tabular}{|c|c|c|c|c|c|c|}
\hline & \multicolumn{2}{|c|}{ Laissez-faire } & \multicolumn{2}{c|}{ FB $(\gamma=0.5)$} & \multicolumn{2}{c|}{ FB $(\gamma=2 / 3)$} \\
\hline Types & $S$ & $L$ & $S$ & $L$ & $S$ & $L$ \\
\hline$c$ & 80 & 76.24 & 77.89 & 77.89 & 111.03 & 55.51 \\
\hline$d$ & 80 & 76.24 & 77.89 & 77.89 & 111.03 & 55.51 \\
\hline$R$ & 61.67 & 70.74 & 61.85 & 70.41 & 59.80 & 76.62 \\
\hline$U$ & 7.095 & 8.324 & 7.039 & 8.381 & 7.741 & 7.384 \\
\hline
\end{tabular}

Table 1: Laissez-faire and first-best for different weights

\begin{tabular}{|c|c|c|c|c|c|c|}
\hline$\gamma$ & \multicolumn{2}{|c|}{0.5} & \multicolumn{2}{c|}{$2 / 3$} & \multicolumn{2}{c|}{ Maximin } \\
\hline Types & $S$ & $L$ & $S$ & $L$ & $S$ & $L$ \\
\hline$c$ & 75.03 & 80.37 & 78.68 & 79.32 & 88.71 & 76.62 \\
\hline$d$ & 73.70 & 80.37 & 65.35 & 79.32 & 50.40 & 76.62 \\
\hline$R$ & 62.03 & 69.93 & 61.09 & 70.13 & 59.67 & 70.66 \\
\hline$t^{\prime}$ & 0.018 & 0 & 0.170 & 0 & 0.432 & 0 \\
\hline$T^{\prime}$ & 0.029 & 0 & 0.254 & 0 & 0.559 & 0 \\
\hline$U$ & 6.953 & 8.464 & 6.978 & 8.429 & 6.996 & 8.337 \\
\hline
\end{tabular}

Table 2: Common social security policy second-best benchmark: different weights

laissez-faire. This effect is reversed when the social weight $\gamma$ is large enough. ${ }^{14}$

\subsection{Second best: common versus differentiated policies}

We present in Table 2 the solution to the second-best with common social security policy across occupations for different weights. ${ }^{15}$ Short-lived individuals are worse-off (and long-lived individuals are better off) than in the first-best. The marginal distortions on both savings and prolonged activity that are imposed on short-lived individuals in the second-best increase with the value of social weight $\gamma$.

We present in Table 3 the second-best with tagging. We do so for different social weights - $\gamma=0.5$ and $\gamma=2 / 3$ - to discuss the implications of increasing the weight, and for different distributions of long-lived and short-lived workers across the occupations - $\left(p_{1}, p_{2}\right)=(0.6,0.4)$ and $\left(p_{1}, p_{2}\right)=(0.8,0.2)$ - to explore the implications of more marked differences in longevity patterns across occupations. Both short- and long-lived workers in the harsh occupations are made better

\footnotetext{
${ }^{14}$ It is possible to find the weight $\gamma$ for which $U_{S}=U_{L}$. For this particular combination of parameters such weight is slightly below $2 / 3$.

${ }^{15}$ In the tables $T^{\prime}$ stands for the marginal tax rate on earnings from prolonged activity to enable relatively straightforward comparison, in terms of magnitude, with traditional optimal income taxes.
} 


\begin{tabular}{|c|c|c|c|c|c|c|c|c|}
\hline \multicolumn{10}{|c|}{$\gamma=0.5$} \\
\hline$\left(p_{1}, p_{2}\right)$ & \multicolumn{9}{|c|}{$(0.6,0.4)$} & \multicolumn{5}{c|}{$(0.8,0.2)$} \\
\hline Types & $S 1$ & $L 1$ & $S 2$ & $L 2$ & $S 1$ & $L 1$ & $S 2$ & $L 2$ \\
\hline$c$ & 75.55 & 80.95 & 74.54 & 79.82 & 76.66 & 82.18 & 73.63 & 78.80 \\
\hline$d$ & 74.47 & 80.95 & 72.95 & 79.82 & 76.11 & 82.18 & 71.57 & 78.80 \\
\hline$R$ & 61.99 & 69.83 & 62.06 & 70.03 & 61.92 & 69.60 & 62.11 & 70.23 \\
\hline$t^{\prime}$ & 0.014 & 0 & 0.021 & 0 & 0.007 & 0 & 0.028 & 0 \\
\hline$T^{\prime}$ & 0.024 & 0 & 0.035 & 0 & 0.012 & 0 & 0.046 & 0 \\
\hline$U$ & 6.969 & 8.482 & 6.938 & 8.446 & 7.003 & 8.522 & 6.909 & 8.412 \\
\hline \hline \multicolumn{8}{|c|}{$\gamma=2 / 3$} \\
\hline$\left(p_{1}, p_{2}\right)$ & \multicolumn{10}{|c|}{} \\
\hline Types & $S 1$ & $L 1$ & $S 2$ & $L 2$ & $S 1$ & $L 1$ & $S 2$ & $L 2$ \\
\hline$c$ & 83.92 & 85.21 & 73.87 & 73.89 & 96.02 & 98.72 & 65.42 & 64.12 \\
\hline$d$ & 73.11 & 85.21 & 58.04 & 73.89 & 90.39 & 98.72 & 44.48 & 64.12 \\
\hline$R$ & 60.85 & 69.08 & 61.32 & 71.24 & 60.35 & 67.16 & 61.72 & 73.72 \\
\hline$t^{\prime}$ & 0.129 & 0 & 0.214 & 0 & 0.059 & 0 & 0.320 & 0 \\
\hline$T^{\prime}$ & 0.198 & 0 & 0.313 & 0 & 0.094 & 0 & 0.440 & 0 \\
\hline$U$ & 7.131 & 8.615 & 6.823 & 8.239 & 7.835 & 8.979 & 6.499 & 7.433 \\
\hline
\end{tabular}

Table 3: Tagging by occupation: different distributions and different weights

off, while those in the safe occupation are made worse-off, by tagging. Short- and long-lived workers in the harsh occupation consume more in both periods and retire earlier than their counterparts in the safe occupation. The differences are more pronounced when the proportion of short-lived individuals in the harsh occupation increases (i.e. occupation 1 becomes harsher). The marginal distortions imposed on the short-lived workers in the safe occupation are larger, and the gap increases (in particular, the distortions on short-lived workers in the safe occupation increase while those on the short-lived workers in the harsh occupation decrease) when occupation 1 becomes harsher. The treatment of individuals in different occupations differs more markedly when the social weight placed on short-lived individuals increases. For the distributions considered in Table 3, the short-lived workers in the safe occupation are made worse-off, while the long-lived workers in the harsh occupation are made better off, by the increase in the social weight placed on short-lived individuals. This suggests that increasing the social weight on short-lived individuals may be a rude instrument to correct for the implicit redistribution towards long-lived when the government is allowed to differentiate the pension policy by occupation: the short-lived individuals in the safe occupation are particularly harmed by the combination of tagging and an increased social weight 


\begin{tabular}{|c|c|c|c|c|c|c|c|c|}
\hline$\left(p_{1}, p_{2}\right)$ & \multicolumn{4}{|c|}{$(0.6,0.4)$} & \multicolumn{4}{c|}{$(0.8,0.2)$} \\
\hline Types & $S 1$ & $L 1$ & $S 2$ & $L 2$ & $S 1$ & $L 1$ & $S 2$ & $L 2$ \\
\hline$c$ & 83.83 & 78.38 & 97.99 & 74.79 & 81.13 & 82.79 & 159.78 & 69.68 \\
\hline$d$ & 57.71 & 78.38 & 41.90 & 74.79 & 70.78 & 82.79 & 20.41 & 69.68 \\
\hline$R$ & 60.27 & 70.31 & 58.94 & 71.05 & 61.06 & 69.49 & 57.11 & 72.22 \\
\hline$t^{\prime}$ & 0.312 & 0 & 0.572 & 0 & 0.128 & 0 & 0.872 & 0 \\
\hline$T^{\prime}$ & 0.430 & 0 & 0.691 & 0 & 0.196 & 0 & 0.919 & 0 \\
\hline$U$ & 7.002 & 8.397 & 7.002 & 8.272 & 7.064 & 8.541 & 7.064 & 8.076 \\
\hline
\end{tabular}

Table 4: Tagging by occupation: maximin, different distributions

\begin{tabular}{|c|c|c|c|c|}
\hline \multicolumn{5}{|c|}{ Second best with tagging } \\
\hline$\gamma$ & \multicolumn{2}{|c|}{0.5} & \multicolumn{2}{c|}{$2 / 3$} \\
\hline$\left(p_{1}, p_{2}\right)$ & $(0.6,0.4)$ & $(0.8,0.2)$ & $(0.6,0.4)$ & $(0.8,0.2)$ \\
\hline$E U_{1}$ & 7.57 & 7.31 & 7.72 & 7.74 \\
\hline$E U_{2}$ & 7.84 & 8.11 & 7.67 & 7.57 \\
\hline
\end{tabular}

Table 5: Expected utility by occupation: different weights and distributions

on short-lived individuals. ${ }^{16}$

We present in Table 4 the solution for the maximin objective for two different distributions of long-lived and short-lived workers across the occupations - $\left(p_{1}, p_{2}\right)=(0.6,0.4)$ and $\left(p_{1}, p_{2}\right)=$ $(0.8,0.2) .{ }^{17}$ In contrast to the previous case, the maximin solution ensures short-lived workers achieve the same utility regardless of occupation. The short-lived workers in the safe occupation face relatively large marginal distortions, which are more pronounced when the proportion of shortlived individuals in the safe occupation is relatively small: they consume the most in the first period, the least in the second period and retire the earliest (i.e. earlier than the short-lived workers in the harsh occupation).

\subsection{Equal expected utility across occupations}

It is worth stressing that in the cases studied above the expected utility generally differs by occupation. In Table 5 we include the expected utility by occupation for the second best with tagging solution in Table 3. With the unweighted utilitarian criterion the expected utility of workers is larger in the safe occupation, but workers in the harsh occupation can be made better off in ex-

\footnotetext{
${ }^{16}$ An alternative criterion to avoid this undesirable result would be to apply a concave transformation to the lifetime individual utilities in the social objective like e.g. Bommier et al. (2011).

${ }^{17}$ We include the statement of the social planner's maximin problem in the appendix.
} 


\begin{tabular}{|c|c|c|c|c|c|c|c|r|}
\hline \multicolumn{1}{|c|}{$\left(p_{1}, p_{2}\right)=(0.6,0.4)$} \\
\hline$\gamma$ & \multicolumn{9}{|c|}{0.5} & \multicolumn{4}{c|}{$2 / 3$} \\
\hline Types & $S 1$ & $L 1$ & $S 2$ & $L 2$ & $S 1$ & $L 1$ & $S 2$ & \multicolumn{1}{|c|}{$L 2$} \\
\hline$c$ & 80.18 & 85.37 & 70.18 & 75.66 & 82.99 & 84.34 & 74.73 & 74.68 \\
\hline$d$ & 79.14 & 85.37 & 68.53 & 75.66 & 72.17 & 84.34 & 58.92 & 74.68 \\
\hline$R$ & 61.59 & 69.06 & 62.48 & 70.86 & 60.91 & 69.23 & 61.25 & 71.07 \\
\hline$t^{\prime}$ & 0.013 & 0 & 0.023 & 0 & 0.130 & 0 & 0.212 & 0 \\
\hline$T^{\prime}$ & 0.021 & 0 & 0.039 & 0 & 0.200 & 0 & 0.309 & 0 \\
\hline$U$ & 7.095 & 8.620 & 6.807 & 8.303 & 7.11 & 8.59 & 6.85 & 8.27 \\
\hline$E U$ & \multicolumn{9}{|c|}{7.70466} & & \multicolumn{5}{c|}{7.69989} \\
\hline
\end{tabular}

Table 6: Equal expected utility by occupation: different weights

pected utility terms if the social weight attached to short-lived individuals is sufficiently large. We have assumed so far that the occupation is given. If workers are unable to choose occupation a policy that favours a particular occupation can be considered unfair. If workers were, on the other hand, able to choose occupations such a policy would not be feasible. In Table 6 we explore the consequences of imposing equal expected utility across occupations. With equal weight $\gamma=0.5$ the equal expected utility constraint induces larger utility differences between individuals with the same longevity and different occupation. This suggests a possible tension between ex-ante equity (equal expected utility regardless of occupation) and ex-post equity (utility achieved by workers of a given longevity type in different occupations). With $\gamma=2 / 3$ the equal expected utility constraint reduces the utility differences between individuals with the same longevity but different occupation.

\subsection{Heterogeneous wages}

We have assumed throughout the paper that both occupations yield the same wage. We have done so to focus on the implications of differential longevity and abstract from the standard redistribution role associated with heterogeneous wages. We illustrate in Table 7 how the results change when wages differ across occupations for two different scenarios: when the wage is lower in the harsh occupation - e.g. $\left(w_{1}, w_{2}\right)=(75,125)$ - and when alternatively the wage is higher in the harsh occupation - e.g. $\left(w_{1}, w_{2}\right)=(125,75)$. The former case fits better with the empirical evidence that workers in highly-qualified occupations live on average longer than manual workers (see e.g. Cambois et al., 2011). In this case the utility differences between two individuals with same longevity but different occupation become more pronounced: the redistribution towards workers in 


\begin{tabular}{|c|c|c|c|c|c|c|c|c|}
\hline \multicolumn{1}{|c|}{$(75,125)=(0.6,0.4), \gamma=0.5$} \\
\hline$\left(w_{1}, w_{2}\right)$ & \multicolumn{9}{c|}{$\left.\mid p_{2}\right)$} & \multicolumn{4}{c|}{$(125,75)$} \\
\hline Types & $S 1$ & $L 1$ & $S 2$ & $L 2$ & $S 1$ & $L 1$ & $S 2$ & $L 2$ \\
\hline$c$ & 77.84 & 81.07 & 74.61 & 82.15 & 75.35 & 83.04 & 76.53 & 79.69 \\
\hline$d$ & 77.20 & 81.07 & 72.35 & 82.15 & 73.81 & 83.04 & 75.59 & 79.69 \\
\hline$R$ & 60.11 & 66.10 & 63.76 & 73.26 & 63.73 & 73.06 & 60.18 & 66.29 \\
\hline$t^{\prime}$ & 0.008 & 0 & 0.030 & 0 & 0.020 & 0 & 0.012 & 0 \\
\hline$T^{\prime}$ & 0.014 & 0 & 0.050 & 0 & 0.034 & 0 & 0.020 & 0 \\
\hline$U$ & 7.130 & 8.619 & 6.807 & 8.354 & 6.833 & 8.385 & 7.095 & 8.579 \\
\hline
\end{tabular}

Table 7: Tagging by occupation: different wages

the harsh occupation due to the lower wage reinforces that due to differential longevity. In contrast to the homogeneous wage case, however, long-lived workers in the safe occupation consume more in both periods than long-lived workers in the harsh occupation, but they retire much later and remain overall worse off. When the wage is larger in the harsh occupation the differential wage and differential longevity forces work in opposite directions. In the example in Table 5 the differential wage effect is sufficiently large so that the results, in terms of utility levels and retirement ages, are reversed: both long- and short-lived individuals in the harsh occupation are worse-off and retire later than their counterparts in the safe occupation.

\section{Conclusions}

In this paper we have explored whether special pension provisions, such as early retirement, should be offered to workers in occupations characterized by lower average life expectancies. We addressed this issue in an optimal non-linear tax setting where individuals differ in longevity and occupation, longevity is private information but is imperfectly correlated with occupation, which can be observed and used as a tag. We adopted a weighted utilitarian social objective, to partially redress the implicit bias towards long-lived individuals that the unweighted utilitarian objective entails, and explored the implications of letting the weights vary. We compared two second-best solutions a common social security policy across occupations and tagging by occupations - and showed that there is a case for differentiating the social security policy by occupation. The second-best solution is characterized by non-distortion on long-lived workers and distortions at both margins - prolonged activity and savings - on short-lived ones. When tagging is allowed the particular bundles allocated 
to each type, and the extent of the distortions on each short-lived type, depend on the proportions of short- and long-lived workers in each occupation.

We performed numerical simulations to illustrate the implications of different policy options. We focused on the welfare achieved by different types of individuals, because the individual utility level remains comparable across all cases, and paid particular attention to the effects associated with increases in the social weight on short-lived individuals. We first compared the laissez-faire and the first-best solutions: we showed how increases in the social weight on short-lived individuals can help redress the implicit bias towards long-lived individuals that the unweighted utilitarian objective entails. We then compared the second-best solution without and with tagging: both short- and long-lived workers in the harsh occupations are made better off, while those in the safe occupation are made worse-off, by tagging. An interesting, and at first sight surprising, result is that an increase in the social weight on short-lived individuals can make short-lived workers in the safe occupation worse off. The short-lived workers in the safe occupation are harmed from being mixed up with a large proportion of long-lived ones even if, as short-lived individuals, they attract a higher weight in the social objective. In asymmetry of information situations the planner may wish to exploit the information that an observable variable (in this case occupation) conveys about the unobservable variable of interest (in this case longevity). The increase in social welfare that tagging (conditioning on the observable variable) brings about is achieved at the expense of horizontal inequities (in this case lower utility of both short- and long-lived workers in the safe occupation, when compared with those with the same longevity in the harsh occupation): the longlived workers in the harsh occupation gain from being mixed up with a large number of short-lived workers, and the short-lived workers in the safe occupation lose from being mixed up with a large number of long-lived workers. The increase in the social weight on short-lived individuals magnifies these effects and can make short-lived workers in the safe occupation worse off, while long-lived workers in the harsh occupation are made better off. These results suggest that increasing the social weight on short-lived individuals is a rude instrument to correct for the implicit bias towards longlived that the unweighted utilitarian social objective entails, particularly if the pension schemes are allowed to differ by occupation. We explored the implications of adopting a maximin criterion instead. In the maximin solution all short-lived types achieve the same utility level but the shortlived workers in the safe occupation face relatively large marginal distortions: they consume the 
most in the first period, the least in the second period and retire the earliest. These marginal distortions are more pronounced, and can indeed be very large, when there is a small proportion of short-lived workers in the safe occupation.

We assumed homogeneous wages across occupations to focus on the differential longevity effect on the pension schemes. We have briefly discussed the implications of allowing wages to differ across occupations: both differential longevity and heterogeneous wages play then a role, in the same or opposite directions depending on whether the harsher occupation is characterized by a lower or a higher wage. For most of the paper we assumed that the occupation was given. The resulting policies, whether common or differentiated by occupation, imply in general differences in expected utility across occupations. We explored the consequences of imposing equality of expected utility across occupations. This constraint ensures that the optimal policy does not favour any particular occupation, which seems undesirable if individuals are unable to choose. It alternatively implies that individuals are ex-ante indifferent between occupations, and that it is possible to have workers in both, if they are able to choose. Numerical results suggest that in some circumstances there may be a tension between ex-ante equity (ensuring equal expected utility across occupation) and ex-post equity (ensuring workers of a given longevity type achieve the same utility regardless of occupation).

It is worth stressing the distinction between these schemes and the special pension provisions in place in many OECD countries that, as Zaidi and Whitehouse (2009) report, typically imply the same treatment is applied to all workers in a given occupation deemed harsh. Our results suggest that special pension provisions may have a role to play but also that they should be sufficiently flexible so as to separate long- and short-lived individuals in each occupation when different longevity types coexist within each occupation.

We have abstracted from political economy considerations. Granting special pension provisions to certain occupations is not without cost when political economy aspects are considered: workers who are well organized are more likely to obtain special provisions and, in a dynamic setting, it may be difficult to withdraw special treatments when formerly harsh occupations turn to be less demanding. The case of railway workers is a canonical example of such evolution. We argue that the pension schemes should be allowed to differ when objective data reflects longevity differences by occupation, and be flexible enough to accommodate changes in circumstances (e.g. if an occupation 
once deemed harsh becomes safer). Indeed our analysis highlights the need to better understand the relationship between occupation and longevity.

\section{References}

[1] Bielecki, M., Goraus, K., Hagemejer, J., Tyrowicz, J., 2016. Decreasing fertility vs increasing longevity: Raising the retirement age in the context of ageing processes. Economic Modelling $52,12-143$.

[2] Bommier, A., Leroux, M-L., Lozachmeur, J-M., 2011. Differential mortality and social security. Canadian Journal of Economics 44, 273-289.

[3] Cambois, E. , Laborde, C., Romieu, I., Robine, J.P., 2011. Occupational inequalities in health expectancies in France in the early 2000s: Unequal chances of reaching and living retirement in good health. Demographic Research 25, article 12, 407-436.

[4] Cremer, H., Lozachmeur, J-M., Pestieau, P., 2004. Social security, retirement age and optimal income taxation. Journal of Public Economics 88, 2259-2281.

[5] Cremer, H., Lozachmeur, J-M., Pestieau, P., 2007. Disability testing and retirement. B.E. Journal of Economic Analysis and Policy 7, article 10.

[6] Eeckhoudt, L., Pestieau, P. 2008. Fear of ruin and longevity enhancing investment. Economics Letters 101, 1-3,

[7] Fleurbaey, M., Leroux, M.L., Ponthière, G., 2014. Compensating the dead. Journal of Mathematical Economics 51(C), 28-41.

[8] Fleurbaey, M., Leroux, M.L., Pestieau, P., Ponthière, G., 2016. International Economic Review $57(1), 177-210$.

[9] Gruber, J., Wise, D. eds., 1999. Social Security Programs and Retirement Around the World. Chicago: University of Chicago Press.

[10] Mao, H., Ostaszewski, K.M., Wang, Y., 2014. Optimal retirement age, leisure and consumption. Economic Modelling 43, 458-464. 
[11] Pestieau, P., Ponthière, G., 2014. Policy implications of changing longevity. CESifo Economic Studies 60 (1), 178-212.

[12] Pestieau, P., Ponthière, G., 2016. Longevity variations and the welfare state. Journal of Demographic Economics 82(2), 207-239.

[13] Pestieau, P., Racionero, M., 2016. Harsh occupations, health status and social security. Journal of Economics 117, 239-257.

[14] Sánchez Martín, A.R., 2010. Endogenous retirement and public pension system reform in Spain. Economic Modelling 27, 336-349.

[15] Sanzenbacher, G.T, Webb, A., Cosgrove, C.M., Orlova, N.S., 2015. Calculating neutral increases in retirement age by socioeconomic status. Center for Retirement Research at Boston College, WP 2015-22.

[16] Zaidi, A., Whitehouse, E.R., 2009. Should Pension Systems Recognize "Hazardous and Arduous Work"?. Social, Employment and Migration Working Paper No. 91, OECD, Paris.

\section{A Maximin}

The social planner problem for the maximin objective is to choose the combinations $\left(c_{i j}, d_{i j}, z_{i j}\right)$ for all $i j$ to maximize

$$
u\left(c_{S 1}\right)+\ell_{S} u\left(d_{S 1}\right)-v\left(z_{S 1} ; \ell_{S}\right)
$$

subject to

$$
\begin{array}{ll}
(\mu): & \sum_{j=1,2} n_{j}\left\{\left(1-p_{j}\right)\left[\left(1+z_{L j}\right) w-c_{L j}-\ell_{L} d_{L j}\right]+p_{j}\left[\left(1+z_{S j}\right) w-c_{S j}-\ell_{S} d_{S j}\right]\right\} \geq 0 \\
\left(\lambda_{1}\right): & u\left(c_{L 1}\right)+\ell_{L} u\left(d_{L 1}\right)-v\left(z_{L 1} ; \ell_{L}\right) \geq u\left(c_{S 1}\right)+\ell_{L} u\left(d_{S 1}\right)-v\left(z_{S 1} ; \ell_{L}\right) \\
\left(\lambda_{2}\right): & u\left(c_{L 2}\right)+\ell_{L} u\left(d_{L 2}\right)-v\left(z_{L 2} ; \ell_{L}\right) \geq u\left(c_{S 1}\right)+\ell_{L} u\left(d_{S 2}\right)-v\left(z_{S 2} ; \ell_{L}\right) \\
(\delta): & u\left(c_{S 2}\right)+\ell_{S} u\left(d_{S 2}\right)-v\left(z_{S 2} ; \ell_{S}\right) \geq u\left(c_{S 1}\right)+\ell_{S} u\left(d_{S 1}\right)-v\left(z_{S 1} ; \ell_{S}\right)
\end{array}
$$

$\delta$ is the Lagrangian multiplier associated with the constraint that ensures that the short-lived individuals in the safe occupation are not made worse off than the short-lived individuals in the harsh occupation. It can be shown that $\delta>0$ so that the constraint that links the two short-lived types is binding. This does not mean that they receive the same bundle but that they achieve the same utility level:

$$
u\left(c_{S 2}\right)+\ell_{S} u\left(d_{S 2}\right)-v\left(z_{S 2} ; \ell_{S}\right)=u\left(c_{S 1}\right)+\ell_{S} u\left(d_{S 1}\right)-v\left(z_{S 1} ; \ell_{S}\right) .
$$




\section{B Equal expected utility across occupations}

The social planner problem for the weighted utilitarian objective, subject to equal expected utility across occupations, is to choose the combinations $\left(c_{i j}, d_{i j}, z_{i j}\right)$ for all $i j$ to maximize

$$
\gamma_{L} \sum_{j=1,2} n_{j}\left(1-p_{j}\right)\left[u\left(c_{L j}\right)+\ell_{L} u\left(d_{L j}\right)-v\left(z_{L j} ; \ell_{L}\right)\right]+\gamma_{S} \sum_{j=1,2} n_{j} p_{j}\left[u\left(c_{S j}\right)+\ell_{S} u\left(d_{S j}\right)-v\left(z_{S j} ; \ell_{S}\right)\right]
$$

subject to

$$
\begin{array}{ll}
(\mu): & \sum_{j=1,2} n_{j}\left\{\left(1-p_{j}\right)\left[\left(1+z_{L j}\right) w-c_{L j}-\ell_{L} d_{L j}\right]+p_{j}\left[\left(1+z_{S j}\right) w-c_{S j}-\ell_{S} d_{S j}\right]\right\} \geq 0 \\
\left(\lambda_{1}\right): & u\left(c_{L 1}\right)+\ell_{L} u\left(d_{L 1}\right)-v\left(z_{L 1} ; \ell_{L}\right) \geq u\left(c_{S 1}\right)+\ell_{L} u\left(d_{S 1}\right)-v\left(z_{S 1} ; \ell_{L}\right) \\
\left(\lambda_{2}\right): & u\left(c_{L 2}\right)+\ell_{L} u\left(d_{L 2}\right)-v\left(z_{L 2} ; \ell_{L}\right) \geq u\left(c_{S 1}\right)+\ell_{L} u\left(d_{S 2}\right)-v\left(z_{S 2} ; \ell_{L}\right) \\
(\varphi): & \left(1-p_{1}\right)\left(u\left(c_{L 1}\right)+\ell_{L} u\left(d_{L 1}\right)-v\left(z_{L 1} ; \ell_{L}\right)\right)+p_{1}\left(u\left(c_{S 1}\right)+\ell_{L} u\left(d_{S 1}\right)-v\left(z_{S 1} ; \ell_{S}\right)\right) \geq \\
& \left(1-p_{2}\right)\left(u\left(c_{L 2}\right)+\ell_{L} u\left(d_{L 2}\right)-v\left(z_{L 2} ; \ell_{L}\right)\right)+p_{2}\left(u\left(c_{S 2}\right)+\ell_{L} u\left(d_{S 2}\right)-v\left(z_{S 2} ; \ell_{S}\right)\right)
\end{array}
$$

$\varphi$ is the Lagrangian multiplier associated with the equal expected utility constraint. It can be shown that this constraint holds. However, in this case it necessary to pay attention to the sense of the inequality constraint. According to Table 5 there are combinations of parameters for which, in the absence of this constraint, the expected utility is larger in the safe occupation whereas other combination of parameters yield the opposite result. The social weight on short-lived individuals plays a crucial role. 